\title{
História, memória e ficção: que fronteiras?
}

\author{
History, Memory and Fiction: What Boundaries?
}

\author{
Sérgio Campos Matos \\ sergiocamposmatos@gmail.com \\ Professor Associado com Agregação \\ Universidade de Lisboa \\ Alameda da Universidade \\ 1600-214 - Lisboa \\ Portugal
}

\section{Resumo}

Sociólogos e historiadores do século XX estabeleceram uma clara distinção entre história e memória. Mas nos últimos decênios tem-se chamado a atenção para aquilo que pode haver de comum entre esses dois campos que nem sempre coincidem. Pretende-se problematizar as complexas relações entre história e memória: as exigências críticas da escrita da história e os registos das diferentes memórias (memória individual, memórias coletivas), equacionando também a relação memória/ esquecimento. E o que distingue a história da ficção? Em que medida podem as memórias ser permeáveis à imaginação? Todos ficcionalizamos o nosso passado. Poder-se-á reduzir a escrita da história a uma dimensão narrativa?

\section{Palavras-chave \\ 11 História; Memória; Fição.}

\begin{abstract}
$20^{\text {th }}$ century sociologists and historians established a clear distinction between history and memory. But in the last decades our attention has been called to what exists in common between these two fields that do not always coincide. In this article, I intend to problematize the complex relationship between history and memory: the critical demands of history writing and the register of various memories (individual memory, collective memory), also equating the relation between memory and forgetting. And what about history? What distinguishes it from fiction? To what extent are memories permeable to imagination? We all fictionalize our past. Could we reduce the writing of history to a narrative dimension?
\end{abstract}

\section{Keywords}

History; Memory; Fiction.

Recebido em: 6/12/2013

Aprovado em: 1/7/2014 


\section{História e memória}

Nos últimos decênios o conceito de memória tem proliferado extraordinariamente, banalizando-se e tornando-se até uma muleta na linguagem científica e na linguagem comum. Como explicar a banalização (mas também revalorização) da memória que remonta aos anos 1970-1980? Foi a partir dessa época que surgiram evidentes sinais de crise no sistema internacional bipolar: de crise (1973) e expansão do capitalismo à escala global, mas também do chamado socialismo de estado na Europa do leste e na URSS. Afirmava-se, entretanto, no mundo ocidental uma teoria neoliberal que difundiu a convicção muito propalada segundo a qual o mercado se autoregula dispensando a intervenção moderadora do Estado e sacrificando solidariedade e justiça social. A mundialização ganhou novos contornos tecnológicos - a era da informática acessível às massas - e mudou profundamente as vivências das pessoas. As noções de espaço e de tempo alteraram-se profundamente. Acentuaram-se os movimentos de emigração e imigração, cresceram os fenômenos de desenraizamento e dissolução de laços nas sociedades tradicionais. Vulgarizaram-se novos suportes de memória, mas revelaram-se ameaças às memórias de grupos humanos minoritários - caso das comunidades rurais que se foram despovoando. Koselleck aludia à aceleração sem precedentes da experiência da modernidade: aceleração do tempo, ruptura com o passado, ruptura com o campo da experiência, com efeitos profundos no vocabulário político e social nos finais do século XVIII e princípios do século XIX (KOSELLECK 1990). Lembre-se, aliás, que já Karl Jaspers, algumas décadas atrás, considerara um novo tipo de consciência histórica a partir do tempo das revoluções liberais: desde a Revolução Francesa, o homem moderno teria passado a ver a sua época por oposição a outras, generalizando-se o sentimento de ruptura com os tempos anteriores (JASPERS 1953, p. 10-24).

O estreitamento da ideia de futuro e, especialmente, das narrativas teleológicas da história exprime-se num refluxo sobre o presente - o presentismo (HARTOG 2003). As ameaças globais - crise financeira, poluição, aquecimento global, fomes, epidemias, narcotráfico - e a mentalidade apocalíptica a elas associada contribui decisivamente para essa centralidade do presente. Até por isso mesmo, o conhecimento do passado continua a ser indispensável para interpelar a complexidade e a dificuldade de compreender o nosso tempo. $\mathrm{E}$ talvez nunca como hoje a procura da memória histórica, das memórias colectivas e individuais seja tão evidente. Vivemos um tempo vertiginoso no ritmo de inovação tecnológica e no excesso de informação instantânea que se difundiram nos finais do século XX. É verdade que a consciência de aceleração do tempo é muito anterior e ficou bem documentada no experimentalismo artístico das vanguardas modernistas, desde o cubismo e o futurismo, nos princípios desse atribulado século. Mas, hoje, quando na Europa ocidental acabaram os camponeses e o mundo rural se esvaziou, o sentimento e a consciência dessa aceleração estão bem mais generalizados.

É certo que os lugares de memória e as ritualizações da memória se multiplicaram como nunca: tudo se patrimonializa, dos sítios naturais às antigas fábricas mortas, das ruínas e da sua ilusão de eternidade ao experimentalismo das 
instalações artísticas, sem esquecer a multiplicação de museus, monumentos, memoriais, arquivos - tudo se comemora. A memória tornou-se objeto de consumo de massas. Mas também é não menos evidente que os não lugares a que se refere Marc Augé invadiram as nossas vidas - autoestradas, apart-hotéis, aeroportos, hospitais e clínicas que lembram escritórios, universidades que lembram hospitais, restaurantes que lembram escritórios. E os lugares de trauma - campos de batalha, prisões, campos de concentração - são objeto de atenção renovada. O trauma traduz-se numa ruptura na memória (LACAPRA 2008, p. 22), produz amnésia, dificuldade de verbalização da experiência. Isso implica também ruptura nas representações de um passado que não passa e não cessa de reinscrever-se no presente, "retorna el recuerdo y el recuento, repetitivo e incesante, de los muertos" (SANFELIPPO 2013, p. 29).

Em tudo isso se pode notar um dos paradoxos do nosso tempo, dividido entre uma cultura quase obsessiva da memória e, por outro lado, uma cultura acelerada de esquecimento - a amnésia acelerada. Já Tony Judt notara esse contraste nos princípios do novo milênio (JUDT 2009; 2010). E o filósofo José Gil aplicava ao caso português o conceito de "não inscrição", isto é, o imediato esquecimento do que acontece no presente (GIL 2005, p. 15-18). Talvez nunca como hoje se esqueçam os mortos e se afaste a morte do frenesim da vida. Mas o passado sempre irrompe no presente. Como afirmava Augusto Comte, os mortos governam os vivos.

Pode então perguntar-se: como se relacionam história e memória? Que diferenças existem entre os registos próprios da história e os registos da memória?

1 16 Trata-se, afinal, de uma questão de limites. Michel de Certeau considerava essa problemática dos limites - ou seja, a diferenciação, a alteridade, a relação com outros discursos - central na ciência histórica (CERTEAU 1975, p. 64-69). Na sociologia francesa do século XX, de Durkheim a Maurice Halbawchs, frisou-se a diferença entre história e memória. Maurice Halbawchs estabelecia uma distinção clara entre memórias colectivas e memória histórica. As memórias colectivas abarcariam num sentido muito amplo o que resta do passado na experiência vivida das comunidades humanas, comunidades urbanas ou rurais, grupos étnicos, profissões, etc. A memória histórica seria o produto de uma tradição historiográfica construida pelos historiadores fora do tempo vivido (mas seria mesmo assim?). Pierre Nora aceitou essa distinção (NORA 1978), caracterizando a memória colectiva como "globalizante e sem fonteira", "fluida", mas dividida. Já a memória histórica seria "analítica e crítica", "precisa e distinta", relevando do exercício da razão e unificando. Lembrava, contudo, Nora que, durante muito tempo, história e memória se haviam mais ou menos confundido, constituindo aquela uma "tradição de memória" (NORA 1984, p. XXII). E, por seu lado, Jacques Le Goff chegou a distinguir em termos demasiado definitivos e estanques duas histórias: a da memória colectiva ("essencialmente mítica, deformada, anacrônica", constituindo "o vivido") e a dos historiadores, devendo esta última "esclarecer" e "rectificar" a primeira (LE GOFF 1984, p. 166). Reconheceu, no entanto, que a história passou a estar muito mais exposta à pressão das memórias colectivas (LE GOFF 1984, p. 44); é o caso das memórias de vivências em regimes ditatoriais ou do Holocausto. 
Na verdade, desde os anos 80, e em particular a partir dos trabalhos reunidos em The invention of tradition (HOBSBAWM; RANGER 1983) e em Les lieux de la memoire (NORA 1984), múltiplas formas de expressão da memória tornaram-se objeto da atenção dos historiadores (os trabalhos de Aby Warburg, de Maurice Halbawchs, e de Frances Yates, que poderiam ser mencionados, não tiveram um impacto imediato comparável ao daquelas obras dos anos 1980). Também a história da história se cultivou como nunca. E esse movimento contribuiu para reposicionar as relações entre história e memória.

Poder-se-á formular a questão a partir das divergências e convergências entre os dois termos. Patrick Lacapra formulou bem o problema: "a memória é simultaneamente mais e menos do que a história e vice-versa. A história pode não capturar nunca alguns elementos da memória: o sentimento de uma experiência, a intensidade da alegria ou do sofrimento" (LACAPRA 2008, p. 34). Como veremos, os historiadores liberais e românticos já estavam conscientes dessa diferença - 0 novelista consegue captar aquilo que o historiador dificilmente é capaz: o sentimento, a imaginação. Por seu lado, a história põe à prova a memória na medida em que se constitui num discurso crítico que se assenta em exigências de prova documental e rigor heurístico e hermenêutico. Envolve uma relação com a alteridade, mas é também um exercício de distanciação em relação ao objeto de estudo, em relação ao outro. Quer isso dizer que não pode envolver empatia com o objeto? Decerto que não. Mas dentro dos limites de uma certa cautela e vigilância crítica. Se o entusiasmo e até a paixão no estudo do passado podem favorecer o historiador e a qualidade do seu trabalho, a verdade é que, se o sentimento não for objeto de controlo, pode cair-se na prática de uma história tribunal (na célebre expressão de Lucien Febvre) que se alimenta de juízos de valor, execrando apologias ou, ao invés, tecendo-as. São bem conhecidos casos em que o sentimento de lealdade patriótica deformou a leitura do passado das nações e comprometeu o rigor histórico.

Guardadas as distâncias, o mesmo é válido para a criação poética. A expressão viva do sentimento não mediatizado por um intenso trabalho intelectual e formal pode comprometer a qualidade artística. Como afirmava Ruy Belo num dos seus poemas, "Não costumo por norma dizer o que sinto/ mas aproveitar o que sinto para dizer qualquer coisa" (BELO 1980, p. 161). E poetas portugueses como Fernando Pessoa, Jorge de Sena ou António Gedeão não chamaram a atenção para a relevância do trabalho intelectual na criação literária? Em 1932, Pessoa criticava os escritores e artistas portugueses por se limitarem a exprimir simples emoções "sem auxílio da inteligência ou da cultura". Criticava-os por ausência de "coordenação pela vontade intelectual dos elementos fornecidos pela emoção" (PESSOA [1946], p. 152).

A memória prolonga o passado no presente, mas, ao invés da história, é "afectiva e mágica" (TRAVERSO 2005, p. 28), está do lado da experiência vivida - nesse sentido, é sempre parcial, ligada aos dados dos sentidos, da imaginação e até dos sonhos (POMIAN 2007, p. 176). Como reconhecia o cineasta espanhol Luis Buñuel no notável livro de memórias que ditou ao seu amigo Jean-Claude Carrière, "A memória é permanentemente invadida pela imaginação e o sonho" (BUÑUEL 1983, p. 9). Acrescentava Buñuel: 
Se me dissessem: faltam-te vinte anos de vida, que queres fazer das vinte e quatro horas de cada um desses dias que vais viver? Respondia: dêem-me duas horas de vida activa e vinte e duas horas de sonho, com a condição de que me possa lembrar dele - porque o sonho só existe através da memória, que o acaricia (BUÑUEL 1983, p. 100).

E refere como exemplo um dos sonhos recorrentes que foi tendo ao longo da vida, o do regresso à sua casa de infância em Calanda (Aragão), no qual se repetia a aparição do espectro do seu pai na noite do velório deste, após a sua morte.

A memória individual - e as memórias colectivas - são sempre selectivas. Todos já tivemos essa experiência banal: lembramos episódios que partilhamos com amigos ou familiares e que eles esqueceram. Ou vice-versa: eles lembram coisas que olvidamos. A história também é seletiva - resulta de escolhas, conscientes ou inconscientes. Escolhemos um tema, uma pergunta, um ponto de vista - uma vista a partir de um ponto. Por que nos interessamos por um determinado tema e não por outro? Como lembra Pomian, a história é seletiva de um modo diverso dos modos da memória; é seletiva de um modo controlado: o historiador é que escolhe o problema, o método ao que vai recorrer (POMIAN 2007 , p. 214). Mas o historiador trabalha com memórias - transmitidas oralmente, por escrito, manifestas ou latentes nos mais variados vestígios deixados pelos homens e mulheres do passado. Nesse sentido, ele é devedor da memória. Por outro lado, não deve esquecer-se que essas memórias são fontes, documentos que, para efetivamente o serem, necessitam ser submetidos a um questionário 118 crítico. Como lembrava o historiador português Vitorino Magalhães Godinho, só são fontes se são construídas e trabalhadas pelo historiador (GODINHO 2009). Isso envolve um esforço de distanciação crítica, de descentragem.

Mais recentemente, Fernando Catroga tem acentuado a relação de proximidade entre a retrospectiva da memória e a restrospectiva historiográfica. A seu ver, há características da memória que também se encontram no trabalho historiográfico: finalismo, presentismo, verossimilhança e representação. $E$, retomando as reflexões de Michel de Certeau, Catroga aproxima a escrita da história do culto dos mortos - a história como um "gesto de sepultura" equiparável à domesticação dos mortos e à linguagem dos cemitérios (CATROGA 2011, p. 34). É um facto que tanto história como memória lidam com a ausência, remetem para objetos ausentes. Em ambas há silêncios e recalcamentos. Mas o trabalho do historiador tem exigências cognitivas e de autenticidade, limites que, obviamente, não estão presentes no funcionamento da memória. Não sendo incompatíveis, memória e história vivem, contudo, numa relação de tensão criativa. Não obstante isso, não creio, como Gerard Noiriel, que todos os escritos de divulgação entrem na categoria de escritos de memória (NOIRIEL 2005, p. 340) - há uma vulgarização produzida por especialistas que mantém as exigências da crítica histórica.

Por seu lado, baseando-se em Paul Ricoeur, Roger Chartier sistematizou as diferenças entre história e memória: 1) a distinção entre testemunho e documento; 2) a diferença entre o carácter imediato da reminiscência e o carácter construído da explicação histórica; 3) a distância entre a fidelidade (ou 
não) da memória e a intenção de verdade da história (CHARTIER 2009, p. 353355), que tem sido sublinhada por tantos historiadores.

Como se sugeriu, a memória é não raro comandada por afetos e associações inesperadas. A simples lembrança - a mneme de Aristóteles - é, em todo o caso, bem distinta da anamnésis (rappel, remémoration), procura ativa que resulta de um esforço voluntário. As memórias podem, pois, ser permeáveis à imaginação. Como notava Paul Ricoeur, há uma memória que imagina, ligada ao sonho, uma espécie de abstração da ação presente ligada ao inútil (RICOEUR 2000). Numerosos exemplos poderíamos dar de textos autobiográficos de grandes escritores e até de historiadores que, de algum modo, idealizaram ou reinventaram o seu passado. O enigma da presença do ausente, como nota o filósofo francês, é comum à imaginação e à memória (RICOEUR 2000, p. 3). Na verdade, a memória é ainda em larga medida um mistério. Como o talento dos artistas é um mistério.

\section{Memória e ficção}

É aqui que interessa estabelecer uma relação entre memória e ficção. Um romancista português do século XX, Vergílio Ferreira, sugeria que a saudade de alguém é saudade de nós. Sublinhava assim a relação intíma entre o eu e os outros próximos na própria construção da identidade individual e da memória. Entre a memória individual e a memória colectiva há um plano intermédio em que os afetos têm grande relevância, em que se estabelece uma relação entre a memória vivida dos indivíduos e a memória pública das comunidades - o plano da relação com os próximos, aqueles que nos aprovam (RICOEUR 2000, p. 161).

Uma pergunta central pode formular-se: como representar o passado - ou seja, o ausente? O que podem ter em comum a esse respeito os registos da história, da literatura, da memória? História, memória e ficção representificam ausências de modos diversos.

A esse respeito, muito antes do chamado linguistic turn, os historiadores românticos deram contributos de grande interesse, que, no entanto, são muitas vezes esquecidos. Tomemos três exemplos. Um deles é o do inglês Macaulay, um dos arautos do que viria a designar-se como wigh paradigm - o modelo da historiografia liberal na Grã-Bretanha. Em 1828, Macaulay escreveu um texto teórico sobre a escrita da história no qual levantava um problema central: o modo de reconstituição do passado que o historiador adopta deve aproximar-se do modo do romance? Se o autor da History of England (1848-1855) se mostrava muito crítico em relação às filosofias racionalistas da história do século XVIII, não deixava de perfilhar o conceito "imaginário" de uma história atenta aos pormenores, ao singular mas também ao colectivo, à parte e ao todo:

O historiador perfeito é aquele em cuja obra o caráter e o espírito de uma época é exibido em miniatura. Ele relata nenhum fato, ele não atribui nenhuma expressão de seu caráter, o que não é autenticado por testemunho suficiente. Mas pela seleção criteriosa, rejeição e arranjo, ele concede à verdade aquelas atrações que foram usurpadas pela ficção. Em sua narrativa uma devida subordinação é observada, algumas transações 
são proeminentes, outras retiradas. Mas a escala em que ele representa é aumentada ou diminuída, não de acordo com a dignidade das pessoas envolvidas nelas, mas de acordo com o grau em que se elucida a condição da sociedade e da natureza do homem. Ele nos mostra o tribunal, o acampamento, e o senado. Mas ele nos mostra também a nação. Ele não considera nenhuma anedota, nenhuma peculiaridade da forma, nenhum ditado familiar, como insignificante demais para sua observação, que não é muito insignificante para ilustrar a operação de leis, da religião e da educação, e para marcar o progresso da mente humana. Os homens não vão apenas ser descritos, mas passarão a ser intimamente conhecidos por nós. As mudanças de costumes serão indicadas, e não apenas por algumas frases gerais ou alguns excertos de documentos estatísticos, mas por imagens apropriadas apresentadas em cada linha (MACAULAY 1828 , p. 4). ${ }^{1}$

Podemos aproximar esse conceito de história da intenção de "ressurreição integral da vida" dos homens do passado, de Jules Michelet: "Ainda mais complicado, mais assustador era meu problema colocado como ressurreição integral da vida, não em suas superfícies, mas em seus organismos profundos e interiores. Nenhum homem sábio o teria imaginado. Felizmente, eu não tinha" (MICHELET 1981, p. 16). ${ }^{2}$

Por seu lado, Herculano comparava a história a uma "coluna polígona de mármore" que o historiador deve contemplar de múltiplos ângulos:

A história pode comparar-se a uma coluna polígona de mármore. Quem quiser examiná-la deve andar ao redor dela, contemplá-la em todas as suas faces. O que entre nós se tem feito, com honrosas excepções, é olhar para um dos lados, contar-Ihe os veios da pedra, medir-lhe a altura por palmos, polegadas e linhas (HERCULANO 1842, p. 220).

Mas, em 1840, antes de se abalançar na produção da sua História de Portugal (1846-1853), Herculano reconhecia que, em certas condições, o novelista podia ser "mais verídico do que o historiador" na sua aproximação ao passado, pois estaria mais familiarizado do que ele em estabelecer um paralelismo entre os sentimentos e o "génio do povo". Que condições eram essas? A seu ver, quando as fontes disponíveis permitiam conhecer o caráter nacional e individual, conhecer a "história íntima dos homens que já não são", a novela podia perscrutar melhor do que a história. Herculano apontava bons exemplos disso: Walter Scott, Victor Hugo, Alfred de Vigny (note-se que este último tinha

\footnotetext{
${ }_{1}^{1}$ No original: "The perfect historian is he in whose work the character and spirit of an age is exhibited in miniature. He relates no fact, he attributes no expression to his character, which is not authenticated by sufficient testimony. But by judicious selection, rejection, and arrangement, he gives to truth those attractions which have been usurped by fiction. In his narrative a due subordination is observed; some transactions are prominent, others retire. But the scale on which he represents them is increased or diminished, not according to the dignity of the persons concerned in them, but according to the degree in which they elucidate the condition of society and the nature of man. He shows us the court, the camp, and the senate. But he shows us also the nation. He considers no anecdote, no peculiarity of manner, no familiar saying, as too insignificant for his notice, which is not too insignificant to illustrate the operation of laws, of religion, and of education, and to mark the progress of the human mind. Men will not merely be described, but will be made intimately known to us. The changes of manners will be indicated, not merely by a few general phrases, or a few extracts from statistical documents, but by appropriate images presented in every line".

2 No original: "Plus compliqué encore, plus effrayant était mon problème posé comme réssurection de la vie intégrale, non pas dans ses surfaces, mais dans ses organismes intérieurs et profonds. Nul homme sage n'y eût songé. Par bonheur, je ne l'était pas".
} 
bem a noção de que a história não penetrava na intimidade do humano). E afirmava, convicto, que, a esse respeito, a novela "conta mais verdades do que boa meia-dúzia de bons historiadores" (HERCULANO 1840, p. 243-244). Em qualquer dos casos, quer em Macaulay, quer em Michelet, quer em Herculano, há uma intenção de alcançar uma história totalizante que represente a vida no seu todo - sem esquecer a sua dimensão íntima.

Como compreender a posição de Herculano, ele que, poucos anos depois, com a sua História de Portugal, contribuiria como ninguém para legitimar a história como disciplina científica autônoma no seu país? Em primeiro lugar, há que lembrar que o maior historiador português do século XIX começou por ser jornalista e novelista histórico, decerto com duas grandes preocupações: a de alargar a instrução popular e o conhecimento do passado nacional. No seu conceito de novela histórica já se encontrava a noção de veracidade - o fundo real dos factos representados literariamente; ou, melhor, de verossimilhança. À intencionalidade vivencial e de verossimilhança acrescentava-se uma preocupação de autenticidade. ${ }^{3}$ Em segundo lugar, as reações públicas que suscitou a publicação do primeiro volume de História de Portugal, sobretudo do lado de um clero conservador, muito centradas na omissão da tradição providencialista do milagre de Ourique como momento de fundação da independência e também no mito da identidade entre portugueses e lusitanos, levaram o historiador a desenvolver uma crítica sistemática à "história fabulosa" - ou seja, a uma história mítica que não diferenciava mito e história -, contribuindo, assim, decisivamente, para a autonomização da história em relação à literatura.

Na novela histórica que se generaliza na primeira metade do séc. XIX há uma intenção de representar e fazer reviver o passado, inventariando ações humanas, caracterizando caracteres, descrevendo ambientes. Trata-se de uma tarefa nada fácil, sobretudo quando se considera que os tempos que se procurava fazer reviver eram tão distantes e tão diversos - a Idade Média. Mas com romancistas como Balzac ou Stendhal, o romance fez-se contemporâneo, dirigiu-se ao presente ou ao passado próximo, num campo de observação alargado em que se multiplicavam horizontes.

No caso de Le rouge et le noir (1830), para a elaboração do romance Stendhal inspirou-se em factos reais relatados (o processo Berthet), dando à obra o um subtítulo significativo: "Chronique de 1830". É sensível a sua preocupação de traçar um quadro da sociedade e dos costumes políticos do seu tempo. Não por acaso, a ação desenvolve-se em três espaços: uma pequena cidade de província em França (Verrières), uma cidade de média dimensão (Besançon) e a capital do país - Paris. Se é evidente que a representação romanesca leva o autor a mergulhar na complexa psicologia das suas personagens e dos seus comportamentos - acima de tudo nos casos de Julien Sorel ou de Mme. de Rênal -, também é verdade que há em Stendhal uma intenção de representação do real que ele próprio teoriza: 
um romance é um espelho que caminha sobre uma grande estrada. Ora ele reflete a nossos olhos o azul dos céus, ora a lama dos lamaçais da estrada. E o homem que carrega o espelho em sua cesta será por vós acusado de ser imortal. Seu espelho mostra a lama, e vocês acusam o espelho (STENDHAL 1991, p. 254). ${ }^{4}$

Julien Sorel, filho de um carpinteiro, excluído da alta sociedade, preceptor de uma família aristocrática, vive clandestinamente o seu amor pela patroa e a sua admiração por Napoleão na França conservadora da Restauração. É herói e anti-herói. O seu percurso é sinuoso, entre o amor e a ambição de ascensão social e de poder. Verdade e ficção estão indissoluvelmente ligadas. É penetrando na subjectividade das suas personagens que Stendhal representa o real. Napoleão, mito secreto de Julien, encarna afinal todo o sonho possível.

Compreende-se assim a capacidade que um grande romancista tem de representar o ausente de um modo mais verossímil do que o historiador poderia fazê-lo. A atenção aos "detalhes, às incertezas, ao aleatório" (HARTOG 2013, p. 178), contribuem decisivamente para esse efeito. Como notou Roland Barthes, com a modernidade emergiu um novo verossímil que foi o realismo, no sentido de "todo o discurso que aceita enunciações creditadas unicamente pelo referente". É certo que a história dotada de uma intenção de captar o "real" de um modo objectivo - a par de outros instrumentos de autentificação como a fotografia, exposições de antiguidades ou culto de lugares de memória - precedeu o realismo na literatura (BARTHES 1987, p. 136). Mas, como podia (ou pode) o \$22 historiador penetrar na "história íntima dos homens que já não são" a que se referia Herculano, quando não há documentos que Ihe forneçam sustentação? Se os comportamentos dos nossos contemporâneos, com quem convivemos, surpreendem-nos a cada dia para o bem e para o mal, se a comunicação entre amigos e entre amantes é tudo menos linear e transparente, ${ }^{5}$ como admitir que a psicologia dos "homens que já não são" se torne diretamente acessível ao historiador? Na verdade, o perfil psicológico de alguém que viveu no passado é irredutível, só poderá oferecer-se ao historiador de um modo mediato, construído, pelos testemunhos que deixou ou pelos testemunhos coevos. E, mesmo assim, dificuldades intansponíveis permanecem. Isso levou o romancista António Lobo Antunes, numa crônica recente, a interrogar-se se "a única biografia possível de um artista não será a da sua obra, página a página, capítulo a capítulo. E a maneira de conhecer o biografado, estudar-lhe o trabalho, porque, ao fim e ao cabo, é o único sítio em que a pessoa está". E, ainda assim, para escrever uma verdadeira biografia, conclui Lobo Antunes metaforicamente, só deixando "muitas páginas em branco. Todas as páginas em branco" (ANTUNES 2012, p. 13).

Pode perguntar-se: e as autobiografias e livros de memórias? Podem ser do maior interesse, sem dúvida. Por tudo o que lá está - e também por aquilo que lá não está, ou seja, pelos silêncios e esquecimentos. Um exemplo ilustrativo

\footnotetext{
${ }^{4}$ No original: "un roman est un miroir qui se promene sur une grande route. Tantot il reflète a nos yeux l'azur des cieux, tantot la fange des bourbiers de la route. Et I'homme qui porte le miroir dans sa hotte sera par vous accusé d'être immoral. Son miroir montre la fange, et vous accusez le miroir".

${ }^{5}$ Para Niklas Luhmann (1999), é mesmo impossível aceder à totalidade do conhecimento do outro na sua plenitude.
} 
disso é o recente e notável livro póstumo de memórias do poeta português António Gedeão, pseudônimo de Rómulo de Carvalho (1906-1997) (CARVALHO 2010) - excelente fonte para uma aproximação ao modo como se vivia num meio de classe média na Lisboa dos anos 1920 e 1930 - surpreende a ausência de referências a acontecimentos internacionais que marcaram a época vivida pelo autor: a Guerra Civil de Espanha, a II Guerra Mundial. Em contrapartida, há muitas e detalhadas páginas dedicadas à família, a surpreendentes vivências de uma família de classe média, às relações entre o autor e os seus pares, entre o autor e os editores. Nesse terreno, é um livro muito revelador de pequenas misérias, mas também de grandezas humanas. Ainda Lobo Antunes diz que se, por hipótese, escrevesse a sua autobiografia, "não publicava a biografia de António Lobo Antunes nenhum, publicava a minha noção dele, dado que aquilo que somos, para nós mesmos, não passa da fantasia do que somos", já que "a vida é um jogo de espectros sinceros" (ANTUNES 2012, p. 12).

Poder-se-á, pois, admitir que num livro de ficção um autor se revela mais do que num livro de memórias ou num diário - como sugeriu um dia um outro romancista português do século XX, Vergílio Ferreira. Creio que sim, se pensarmos que, num romance, a pluralidade de vozes torna mais fácil a expressão da intimidade, daquilo que num registo autobiográfico tende a ser mais facilmente autocensurado ou ocultado. O romance exprime a imaginação moral multiplicando experiências de vida eexperiências vividas.

E a historiografia? Consegue dar vida às personalidades que retrata? Direi que com maior dificuldade, pois, como sabemos, os historiadores preocupam-se sobretudo com a veracidade. E ela tem os seus limites. Há sempre zonas obscuras e não esclarecidas na vida dos nossos antepassados. Como observou o historiador catalão Jordi Canal numa recente conferência em Lisboa, os historiadores tendem a ver as pessoas do passado de um modo mais lógico. Sem os constrangimentos da fundamentação e da verdade, os romancistas podem dar largas à imaginação, podem multiplicar as vidas - como um compositor num concerto multiplica sons. Nesse sentido, a multiplicidade de pontos de vista que encontramos num grande romance (incluindo o do narrador) pode ser vista como uma polifonia. E os próprios parâmetros éticos e de verdade são móveis. Onde está o bem e o mal em Crime e castigo de Dostoievsky? Ou na vida do estudante Rastignac, personagem principal de Le pére Goriot, de Balzac? Este é um exercício evidentemente vedado ao historiador profissional dos nossos dias.

Ora, com o chamado linguistic turn, esbateram-se as fronteiras entre história e literatura, o que suscitou um debate muito frutuoso. A voga do estruturalismo levou a uma aproximação entre história e linguística - como, aliás, já se haviam verificado aproximações com outras ciências humanas. Um exemplo disso são os trabalhos de Régine Robin (ROBIN 1973). Admitia-se que toda a "realidade histórica" era mediatizada pelo discurso e, mais, que a história se reduzia à dimensão discursiva. Rolland Barthes chegou a afirmar que "o discurso histórico é essencialmente elaboração ideológica ou, para sermos mais precisos, imaginária" (BARTHES 1987, p. 128). Só os discursos pareciam interessar na sua imanência, na sua autonomia. Desvalorizavam-se os autores 
(FOUCAULT 1970). Um século depois do pico de voga do cientismo, o discurso da história voltava a aproximar-se - agora em novos termos - dos discursos da literatura. Os trabalhos de Hayden White (WHITE 1992) e de Paul Veyne (VEYNE 1983) para tanto contribuiriam decisivamente. White valorizava as estratégias linguísticas na estruturação e legitimação das diversas interpretações da história. Se é certo que negava à história um estatuto científico, não deve esquecer-se que estava bem consciente da distinção entre história e novela (WHITE 1992, p. 17). Por seu lado, Paul Veyne afirmava que a história é "romance verdadeiro" e também Ihe recusava o estatuto de ciência. E no final dessa década de 1970, quando tanto mudou na vida da humanidade, Lawrence Stone procurava explicar a revalorização da dimensão narrativa da história a partir da influência da antropologia, da história intelectual e do interesse pelas estruturas mentais, sem esquecer a intenção de tornar a historiografia mais acessível ao público (STONE 1986). Em todas essas reflexões estava em causa a própria natureza da escrita da história e o estatuto da disciplina.

Outros iam bem mais longe, questionando a própria "realidade histórica": tudo em história tendia a reduzir-se a representações - re(a)presentações de ausências. A realidade parecia deixar de existir fora da linguagem. Esqueciase que as representações não são produzidas fora dos seus contextos e que o conhecimento desses contextos e dos seus autores é relevante. Como compreender, por exemplo, o complexo fenômeno da emigração europeia para as Américas sem ter em conta os problemas demográficos, econômicos e sociais das sociedades de origem, as motivações e expectativas de futuro dos emigrantes, as características das sociedades de destino e as suas necessidades - entre outros factores? Ou como compreender a prática da escravatura no espaço atlântico dos tempos modernos se nos ativermos apenas ao plano dos discursos - tanto mais que eles se limitam, majoritariamente, aos testemunhos dos senhores de escravos?

A reação ao linguistic turn não se fez esperar. O seu balanço crítico já foi empreendido (NOIRIEL 2005, p. 154-176; SPIEGEL 2009; DELACROIX 2011). Não voltarei a ele. Importa, sim, notar que, recentemente, diversos historiadores têm sublinhado as diferenças irredutíveis entre os dois géneros - história e literatura - tendo em conta a fundamentação do primeiro na investigação científica (NORA 2011, p. 7). Noutro ângulo de abordagem, outros notam a incerteza de fronteiras e os diferentes pactos que esses gêneros diversos estebelecem com os seus leitores, sem esquecer o quanto a história pode contribuir para a imaginação literária e, por outro lado, o quanto essa última pode fazer notar aos historiadores a dimensão da contingência e do acaso (OZOUF 2011, p. 18-24).

A história ajuda a compreender os problemas humanos do passado - e até do presente. Mas não deve preocupar-se em julgar os homens. O que menos interessa é o juízo de valor e a adjetivação, em que são tão férteis alguns historiadores. Esses exercícios, entre muitos outros, claro está, não estão vedados ao ficcionista e ao memorialista. Toda a história é narrativa. Quer isso dizer que se possa limitar a uma dimensão narrativa? De modo algum. Sempre haverá mútiplas historiografias. Mas será sempre desejável uma história reflexiva e problematizante, que rasgue novos horizontes de compreensão da experiência humana. 


\section{Referências bibliográficas}

BARTHES, Rolland. O efeito de real. In: O rumor da língua. Lisboa: Edições 70, 1987 [1968], p. 131-136.

BELO, Ruy. Outono. In: Homem de palavras. Obra poética. Lisboa: Presença, 1980.

BUÑUEL, Luis. O meu último suspiro. Lisboa: Distri Editora, 1983.

CARVALHO, Rómulo de. Memórias. Lisboa: FCG, 2010.

CATROGA, Fernando. Os passos do homem como restolho do tempo: memória e fim do fim da história. 2a edição. Coimbra: Almedina, 2011.

CERTEAU, Michel de. L'écriture de I'histoire. Paris: Gallimard, 1975.

CHARTIER, Roger. Au bord de la falaise: I'histoire entre certitudes et inquiétude. Paris: Albin Michel, 2009.

DELACROIX, C. Linguistic turn. In: DELACROIX, C. et al. (dir.). Historiographies I: concepts et débats. Paris: Gallimard, 2010. p. 476-490.

FOUCAULT, Michel. L' ordre du discours. Paris: Gallimard, 1971.

GIL, José. Portugal, hoje: o medo de existir. 5a edição. Lisboa: Relógio de Água, 2005.

GODINHO, Vitorino Magalhães. Da dificuldade de pensar o nosso tempo. In: . Estudos e ensaios. V. I. Lisboa: João Sá da Costa, 2009, p. 25-76.

HARTOG, François. Regimes d'historicité: présentisme et experiences du temps. Paris: Seuil, 2003.

Croire en I'histoire. Paris: Flammarion, 2013.

HERCULANO, Alexandre. Moral. Velhice. O Panorama, v. 4, p. 243-244, 1840. . Cartas sobre a História de Portugal. In: Opúsculos IV. Lisboa: Ed. Presença, 1985 [1842], p. 189-239.

HOBSBAWM, Eric; RANGER, Terence (eds.). The Invention of Tradition. Cambridge: Cambridge University Press, 1983.

JASPERS, Karl. La situation spirituelle de notre époque. Paris-Louvaina: D. De Brouwer/E. Nauwelaerts, 1953.

KOSELLECK, Reinhart. Le futur passé: contribution à la sémantique des temps historiques. Paris: EHESS, 1990.

JUDT, Tony. $\mathbf{O}$ século XX esquecido: lugares e memórias. Lisboa: Edições 70, 2009.

Pós-Guerra: história da Europa desde 1945. Lisboa: Presença, 2010 [2005].

LACAPRA, Dominick. Historia y memoria después de Auschwitz. Buenos Aires: Prometeo, 2008. 
LE GOFF, Jacques. História. In: Enciclopédia Einaudi. V. I: MemóriaHistória. Lisboa: INCM, 1984.

LUHMANN, Niklas. A improbabilidade da comunicação. Lisboa: Vega, 1999.

MACAULAY. The Task of the Modern Historian. Disponível em: http://www. blupete.com/Literature/Essays/Best/MacaulayModHis. Acesso em: 4 dez. 2013.

MICHELET, Jules. Histoire de France: le Moyen Âge. Apresentação de Claude Mettra. Paris: R. Laffont, 1981 [1869].

NOIRIEL, Gérard. Sur la "crise" de I'histoire. Paris: Gallimard, 2005.

NORA, Pierre. Mémoire collective. In: LE GOFF, Jacques; CHARTIER, Roger; REVEL, Jacques (dir.). La Nouvelle Histoire. Paris: CEPL, 1978, p. 298401.

Entre mémoire et histoire. La problématique des lieux. In: Les lieux de la mémoire. V. I. Paris: Gallimard, 1984, p. XVII-XLII.

. Histoire et roman: où passent les frontiers? Le Débat, n. 165, p. 6-12, 2011.

OZOUF, Mona. Récit des romanciers, récit des historiens. Le Débat, n. 165, p. 13-25, 2011.

PESSOA, Fernando. O caso mental português [1932]. In: SENA, Jorge de (ed.).

Páginas de doutrina e estética. $2^{a}$ edição. Lisboa: Editorial Inquérito, [1946], p. 143-153.

POMIAN, K. Sobre la historia. Madrid: Cátedra, 2007.

RICOEUR, Paul. La mémoire, I’hstoire, l'oubli. Paris: Seuil, 2000.

ROBIN, Régine. Histoire et Linguistique. Paris: Armand Colin, 1973.

SANFELIPPO, Luis El trauma en la historia. Razones y problemas de una importación conceptual. Pasajes. Valencia, n. 40, p. 24-37, 2012-2013.

SPIEGEL, Gabrielle M. The Task of the Historian. The American Historical Review, n. 114, p. 1-15, 2009.

STENDHAL. Le Rouge et le Noir. Paris: Gallimard, 1991 [1830].

STONE, Lawrence. El resurgimiento de la narrativa: reflexiones acerca de una nueva y vieja historia. In: El pasado y el presente. México: Fondo de Cultura Económica, 1986 [1979], p. 95-120.

TRAVERSO, Enzo. Le passé, modes d'emploi.: histoire, mémoire, politique. Paris: La Fabrique Ed., 2005.

VEYNE, Paul. Como se escreve a história. Lisboa: Edições 70, 1983 [1971].

WHITE, Hayden. Metahistoria: la imaginación histórica en la Europa del siglo XIX. México: Fondo de Cultura Económica, 1992 [1973]. 